\title{
Structural analysis and macrophage activation of a novel $\beta$-glucan isolated from Cantharellus cibarius
}

\author{
YUNHE QU, XIAOLIN ZHAO, HUIJUN GUO, YUE MENG, YUMENG WANG, YIFA ZHOU and LIN SUN \\ Engineering Research Center of Glycoconjugates Ministry of Education, \\ Jilin Provincial Key Laboratory on Chemistry and Biology of Changbai Mountain Natural Drugs, \\ School of Life Sciences, Northeast Normal University, Changchun, Jilin 130024, P.R. China
}

Received October 15, 2020; Accepted January 12, 2021

DOI: $10.3892 /$ ijmm.2021.4883

\begin{abstract}
The present study was designed to investigate the structure and immunomodulatory activity of a polysaccharide. A novel acidic $\beta$-glucan (WCCP-A-b; molecular weight, $7.3 \mathrm{kDa}$ ) was purified from the fruiting bodies of the edible mushroom Cantharellus cibarius, which possesses high nutritional values. WCCP-A-b was composed primarily of glucose $(89.7 \%)$ and glucuronic acid (8.8\%). Methylation and nuclear magnetic resonance analysis suggested that WCCP-A-b contained $\beta$-D-1,6-glucan as its main chain, which was substituted at O-3 by $\beta-1,3-\mathrm{D}-\mathrm{Gl} p$ oligosaccharides or a single-unit of $\beta$-Glc $p$ residues. Minor $\beta-1,4-\mathrm{D}-\mathrm{Glc} p \mathrm{~A}$ residues may also be present in the side chains. The degree of branching was $\sim 20.9 \%$. Moreover, WCCP-A-b possessed a macrophage activating effect by promoting the secretion of nitric oxide, TNF- $\alpha$ and IL- 6 in a dose-dependent manner. At a cellular mechanistic level, WCCP-A-b activated macrophages via the MAPK signaling pathway. The present results provided useful information for supporting further investigations on the structure-activity association of polysaccharides from C. cibarius, and indicated that the novel $\beta$-glucan may be a potent natural immunomodulator, thus promoting the application of $C$. cibarius as a valuable source for functional food.
\end{abstract}

\section{Introduction}

Mushrooms have been widely used and consumed as part of the human diet in numerous countries for centuries due to their high nutritional values, since they contain high protein and fiber contents with small amounts of fat (1). Additionally,

Correspondence to: Dr Lin Sun, Engineering Research Center of Glycoconjugates Ministry of Education, Jilin Provincial Key Laboratory on Chemistry and Biology of Changbai Mountain Natural Drugs, School of Life Sciences, Northeast Normal University, 5268 Renmin Street, Changchun, Jilin 130024, P.R. China

E-mail: sun1925@nenu.edu.cn

Key words: Cantharellus cibarius, polysaccharide, glucan, structural analysis, macrophage activation mushrooms are sources of minerals, such as calcium, zinc and magnesium, and vitamins (2). Recently, the medicinal properties of mushrooms have attracted increasing attention. Polysaccharides are the main active ingredients of edible mushrooms (3). Moreover, mushroom polysaccharides, which have been isolated from the fruiting bodies, mycelia and culture media, serve an important role in the growth and development of fungal organisms and have abundant activities, such as antioxidant, anti-inflammatory, anticancer, antidiabetic and immunomodulatory effects (4).

Glucans are considered as one of the most essential polysaccharides in mushrooms, based on their diversified chemical structures and marked medicinal effects (5). Glucans have been discovered in numerous Basidiomycetes in the form of $\alpha-1,3$-D-glucans (6), $\alpha-1,4-\mathrm{D}$-glucans (7), $\beta$-1,3-D-glucans (8) and $\beta-1,6-\mathrm{D}$-glucans (9). The differences in structure among these glucans may affect their biological properties. A recent study has revealed that $\alpha-1,6$-D-glucans and $\beta-1,3$-D-glucans isolated from the basidiome and the mycelium of Pleurotus albidus differentially inhibit lipid-induced inflammation and pro-inflammatory lipid-laden macrophage (foam cell) formation in macrophage-like cells (10). Additionally, it has been demonstrated that linear $\beta$-( $1 \rightarrow 3$-D-glucan from Cordyceps militaris exerts an anti-inflammatory effect in vitro and in vivo (11). The linear ( $1 \rightarrow 6)$ - $\beta$-D-glucan of Agaricus bisporus has an effect on the expression levels of pro-inflammatory genes and significantly inhibits the production of inflammatory cytokines caused by lipopolysaccharide (LPS) (9). Furthermore, a branched 1,3- $\beta$-D-glucan, which is obtained from Sparassis crispa, stimulates leukocytes of DBA/2 mice and secretes cytokines in vitro, indicating its immunological activity (12). Previous studies have reported that $\beta-1,3$-D-glucan with a branching degree (DB) between 0.20 and 0.33 present the most potent antitumor effects (13-15), while the $\beta-1,3-\mathrm{D}$-glucan with a DB that is too high or too low is not effective (16). The linear $\alpha-1,3$-glucan and branched $\beta-1,3 / 1,6$-glucan from the stems of Pleurotus eryngii and Pleurotus ostreatus exhibit potential prebiotic activity by regulating the growth of Lactobacillus, Bifidobacterium and Enterococcus (17).

Macrophages are innate immune cells present in every tissue and are necessary for normal tissue development, homeostasis and repair of damaged tissues (18). Activated macrophages can phagocytose and neutralize cancer cells 
by secreting nitric oxide (NO), TNF- $\alpha$ and IL-6 cytokines. Polysaccharides have been reported to exert immune and antitumor activities by regulating macrophage activities $(19,20)$. For example, a polysaccharide from Ganoderma sinense (GSP-2) specifically upregulates the protein expression levels of Toll-like receptor 4 and activates the MAPK signaling pathway in RAW246.7 macrophages. Moreover, GSP-2 exerts its immunomodulatory activity by inducing the secretion of the cytokines TNF- $\alpha$, IL-1 $\beta$ and IL-6 (21). Additionally, it has been reported that a water-soluble $\beta$-D-glucan obtained from Hericium erinaceus is able to induce the proliferation of lymphocytes and improve the expression levels of inflammatory cytokines produced by THP-1 macrophages (22).

Cantharellus cibarius is a common wild edible mushroom belonging to the phylum Basidiomycota. Polysaccharides are one of the main active ingredients of $C$. cibarius (23). A linear $\alpha-1,6-D-m a n n a n$ and a branched $\alpha-1,6-D-m a n n a n$ substituted with mannan side chains can be isolated from the fruiting bodies of C. cibarius (24-26). Our previous study indicated that linear 3-O-methylated galactan isolated from $C$. cibarius activated macrophages and modulated the antitumor immune response by converting tumor-associated macrophages towards an M1-like phenotype $(27,28)$. In addition, $C$. cibarius contains various types of glucans. $\alpha-1,6-\mathrm{D}$-glucan with $\beta-1,4-\mathrm{D}-\mathrm{Glc} p$ side chains is extracted using boiling water, and $\beta-1,3$-D-glucan branched at O-6 and a $\beta-1,6-\mathrm{D}$-glucan with single and short side chains can be separated from the hot aqueous $\mathrm{NaOH}$ fraction $(26,29)$. The present study reported the extraction and purification of a novel acidic $\beta$-glucan from the fruiting bodies of $C$. cibarius and characterized its structure. The immunomodulatory activity of the acidic $\beta$-glucan was further investigated.

\section{Materials and methods}

Materials. Fruiting bodies of $C$. cibarius were purchased from the Guilin Road Market (Changchun, China) and were identified using rDNA-Internal Transcribed Spacer sequencing analysis (27). Anion-exchange chromatography (DEAE-cellulose) was purchased from Amersham (Cytiva). Sepharose CL-6B was purchased from Cytiva, while LPS and Polymyxin B sulfate (PMB) were obtained from Sigma-Aldrich (Merck KGaA). TNF- $\alpha$ (cat. no. EK0527) and IL-6 ELISA kits (cat. no. EK0411) were obtained from Boster Biological Technology. Nembutal was acquired from Sinopharm Chemical Reagent Co., Ltd. SB203580 (cat. no. S1863), U0126 (cat. no. S1901) and SP600125 (cat. no. S1876) were acquired from Beyotime Institute of Biotechnology. All of the other reagents were of analytical grade or higher.

Extraction and purification of the polysaccharides. Fruiting bodies of $C$. cibarius were first extracted with distilled water at $100^{\circ} \mathrm{C}$ for $4 \mathrm{~h}(1: 25 \mathrm{w} / \mathrm{v})$, followed by another extraction at $100^{\circ} \mathrm{C}$ for $2 \mathrm{~h}(1: 20 \mathrm{w} / \mathrm{v})$. The hot water extracts were concentrated under a vacuum at $60^{\circ} \mathrm{C}$ and precipitated using $4 \mathrm{X}$ volumes of $95 \%$ ethanol at room temperature for $12 \mathrm{~h}$. The precipitate was collected via centrifugation $(3,200 \mathrm{x} \mathrm{g}$ for $15 \mathrm{~min}$ ) at $25^{\circ} \mathrm{C}$ and re-dissolved in water, dialyzed and lyophilized to obtain the polysaccharide named water-soluble C. cibarius polysaccharide (WCCP).
WCCP was dissolved in distilled water, added to a DEAE-cellulose column $\left(8.0 \times 20 \mathrm{~cm} ; \mathrm{Cl}^{-}\right)$pre-equilibrated with distilled water for anion-exchange chromatography (27) and eluted with distilled water to yield a neutral polysaccharide fraction (WCCP-N) or $0.3 \mathrm{M} \mathrm{NaCl}$ to obtain an acidic polysaccharide fraction (WCCP-A). WCCP-A was further purified via gel-permeation chromatography (Sepharose CL-6B), the eluate was collected and the absorbance was measured at $490 \mathrm{~nm}$ for total sugar to give a homogeneous fraction (WCCP-A-b), as previously described by Yang et al (27).

General methods. The total carbohydrate content was determined using the phenol-sulfuric acid protocol with glucose as the standard (30). Uronic acid content was determined using the colorimetric method with glucuronic acid as the standard (31). Protein content was determined using the Bradford assay with BSA (VWR International, LLC) as the standard (32).

Homogeneity and molecular weight determination. Molecular weight distributions were determined using high-performance gel permeation chromatography (HPGPC) with a TSK-gel G-3000PWXL (7.8x300 mm; Tosoh Corporation) coupled to a Shimadzu high-performance liquid chromatography (HPLC) system (LC-10ATvp pump and refractive index RID-10A detector) as described by Zhang et al (33). The column was pre-calibrated using standard dextrans $(50,25,12$, 5 and $1 \mathrm{kDa}$ ) and linear regression.

Monosaccharide composition analysis. Monosaccharide composition was determined using HPLC as described by Zhang et al (33). Briefly, polysaccharide samples (2 mg) were first hydrolyzed with $1 \mathrm{ml}$ anhydrous methanol containing $2 \mathrm{M}$ $\mathrm{HCl}$ at $80^{\circ} \mathrm{C}$ for $16 \mathrm{~h}$ and then with $1 \mathrm{ml} 2 \mathrm{M}$ trifluoroacetic acid at $120^{\circ} \mathrm{C}$ for $1 \mathrm{~h}$. Following derivatization with 1-phenyl3-methyl-5-pyrazo-lone, the derivatives were analyzed using a Shimadzu HPLC system.

Fourier transform infrared (FT-IR) spectroscopy. Polysaccharides were ground with $\mathrm{KBr}$ powder and turned into a pellet that was $\sim 1 \mathrm{~mm}$ for subsequent FT-IR analysis, as previously described (34). FT-IR spectra were obtained with a Spectrum Two FT-IR spectrometer in the range of 4,000-400 $\mathrm{cm}^{-1}$ (PerkinElmer, Inc.).

Methylation analysis. Methylation analysis was conducted according to the method of Needs and Selvendran (35). Uronic acid was firstly reduced into neutral sugars using $\mathrm{NaBD}_{4}$ prior to methylation analysis. Subsequently, the reduced polysaccharide $(5 \mathrm{mg})$ was dissolved in DMSO $(0.5 \mathrm{ml})$ and methylated with a suspension of $\mathrm{NaOH} / \mathrm{DMSO}(0.5 \mathrm{ml})$ and iodomethane $(1.0 \mathrm{ml})$. The reaction mixture was extracted with $\mathrm{CH}_{2} \mathrm{Cl}_{2}$, and then the solvent was removed via vacuum evaporation. Complete methylation was confirmed by the disappearance of the -OH band $\left(3,200-3,400 \mathrm{~cm}^{-1}\right)$ in the FT-IR spectrum. The per-O-methylated polysaccharide was subsequently hydrolyzed using $\mathrm{HCOOH}(85 \% ; 1 \mathrm{ml})$ for $4 \mathrm{~h}$ at $100^{\circ} \mathrm{C}$ and then $\mathrm{CF}_{3} \mathrm{COOH}(2 \mathrm{M} ; 1 \mathrm{ml})$ for $6 \mathrm{~h}$ at $100^{\circ} \mathrm{C}$. The partially methylated sugars in the hydrolysate were reduced using $\mathrm{NaBH}_{4}$ and were then acetylated. The resulting alditol acetates were analyzed using gas chromatography-mass 
spectrometry (GC-MS; 7890B-5977B; Agilent Technologies, Inc.) with a DB-35 ms capillary column (30 m x $0.32 \mathrm{~mm} \times$ $0.25 \mathrm{~mm}$ ), as previously described (27). The oven temperature was programed from $120^{\circ} \mathrm{C}$ (hold for $1 \mathrm{~min}$ ) to $210^{\circ} \mathrm{C}$ (hold for $2 \mathrm{~min}$ ) at $3^{\circ} \mathrm{C} / \mathrm{min}$, then up to $260^{\circ} \mathrm{C}$ (hold for $4 \mathrm{~min}$ ) at $10^{\circ} \mathrm{C} / \mathrm{min}$. The temperature of both the inlet and detector was $300^{\circ} \mathrm{C}$. Helium was used as the carrier gas. The mass scan range was $50.0-500.0 \mathrm{~m} / \mathrm{z}$.

Nuclear magnetic resonance $(N M R)$ analysis. ${ }^{1} \mathrm{H},{ }^{13} \mathrm{C}$, heteronuclear singular quantum correlation (HSQC) and heteronuclear multiple bond correlation (HMBC) NMR spectra were recorded at $20^{\circ} \mathrm{C}$ on a Bruker Avance $600 \mathrm{MHz}$ spectrometer (Bruker Corporation) with a Bruker 5-mm broadband probe, operating at $600 \mathrm{MHz}$ for ${ }^{1} \mathrm{H} \mathrm{NMR}$ and $150 \mathrm{MHz}$ for ${ }^{13} \mathrm{C} \mathrm{NMR}$. Polysaccharides $(20.0 \mathrm{mg})$ were dissolved in $\mathrm{D}_{2} \mathrm{O}(0.5 \mathrm{ml})$ and centrifuged at $10,462 \mathrm{x}$ g for $3 \mathrm{~min}$ at $25^{\circ} \mathrm{C}$ to remove any undissolved polysaccharide. Data were analyzed using standard Bruker software (MestReNova v10.0; Bruker Corporation).

Cell culture. RAW264.7 cells were purchased from the American Type Culture Collection. Cells were cultured in DMEM (Gibco; Thermo Fisher Scientific, Inc.) high glucose medium supplemented with $100 \mathrm{U} / \mathrm{ml}$ penicillin, $100 \mu \mathrm{g} / \mathrm{ml}$ streptomycin and 10\% heat-inactivated FBS (Gibco; Thermo Fisher Scientific, Inc.). RAW264.7 cells were maintained at $37^{\circ} \mathrm{C}$ in a $5 \% \mathrm{CO}_{2}$ incubator.

Animals. Specific-pathogen-free female Balb/c mice (10 mice; age, 6-8 weeks; weight, 16-18 g) were obtained from Beijing HFK Bioscience Co., Ltd. Animal experiments were conducted in compliance with the Animal Management Rules of the Ministry of Health of the People's Republic of China and were approved by the Animal Care and Use Committee of Northeast Normal University (Changchun, China). All animals were kept at a constant temperature of $21^{\circ} \mathrm{C}$, relative humidity of $55 \%$ and under a 12-h light-dark cycle. The animals were maintained under pathogen-free conditions and allowed access to food and water ad libitum. Nembutal (50 mg/kg) was injected intraperitoneally into Balb/c mice. After being anesthetized, mice were sacrificed by cervical dislocation. A single cell suspension of peritoneal macrophages and bone marrow macrophages were prepared from Balb/c mice under aseptic conditions by frosted slides in PBS. The suspension was centrifuged at $400 \mathrm{x} \mathrm{g}$ for $3 \mathrm{~min}$ at $4^{\circ} \mathrm{C}$ to obtain the cell pellet. After two washes in PBS, the cells were resuspended in complete DMEM for subsequent examinations.

Cell viability assay. RAW264.7 cells were seeded at a density of $5 \times 10^{4}$ cells/well in a 96 -well plate overnight at $37^{\circ} \mathrm{C}$ and were then treated with various concentrations $(0,25,50$, 100 and $200 \mu \mathrm{g} / \mathrm{ml}$ ) of WCCP-A-b or $1 \mu \mathrm{g} / \mathrm{ml} \mathrm{LPS} \mathrm{at} 37^{\circ} \mathrm{C}$ for $24 \mathrm{~h}$. The medium was removed, and $100 \mu \mathrm{l} /$ well of MTT solution $(0.5 \mathrm{mg} / \mathrm{ml})$ was added. After a 4 -h incubation at $37^{\circ} \mathrm{C}$, supernatants were discarded and the resulting formazan was dissolved in $100 \mu \mathrm{l}$ DMSO. The absorbance was measured at $570 \mathrm{~nm}$ using a microplate reader (BioTek Instruments, Inc.; Agilent Technologies, Inc.). Cell proliferation was expressed as the percentage of the control, which was set to $100 \%$. To examine the effect of endotoxin contamination, the polysaccharides were pre-treated with PMB $(30 \mu \mathrm{g} / \mathrm{ml})$ for $24 \mathrm{~h}$ at $37^{\circ} \mathrm{C}$ and then used for cell viability assays.

Measurement of NO. RAW264.7 cells, mouse peritoneal macrophages and bone marrow macrophages were seeded at a density of $1 \times 10^{5}$ cells/well in a 48 -well plate overnight at $37^{\circ} \mathrm{C}$ and were then treated with various concentrations $(0,25,50$, 100 and $200 \mu \mathrm{g} / \mathrm{ml}$ ) of WCCP-A-b or $1 \mu \mathrm{g} / \mathrm{ml} \mathrm{LPS}$ at $37^{\circ} \mathrm{C}$ for $24 \mathrm{~h}$. After incubation, supernatants were collected and reacted with Griess reagent as previously described (36).

Measurement of TNF- $\alpha$ and IL-6. RAW264.7, mouse peritoneal macrophages and bone marrow macrophages were seeded at a density of $1 \times 10^{5}$ cells/well in a 48 -well plate overnight at $37^{\circ} \mathrm{C}$ and were then treated with various concentrations of WCCP-A-b $(0,25,50,100$ and $200 \mu \mathrm{g} / \mathrm{ml})$ or $1 \mu \mathrm{g} / \mathrm{ml} \mathrm{LPS}$ at $37^{\circ} \mathrm{C}$ for $24 \mathrm{~h}$. The concentrations of TNF- $\alpha$ and IL- 6 in the supernatants were assessed using the aforementioned TNF- $\alpha$ and IL-6 ELISA kits according to the manufacturer's instructions.

Western blotting. RAW264.7 cells were seeded at a density of $8 \times 10^{5}$ cells/well in a 6 -well plate, and were then pretreated with or without specific inhibitors $(25 \mu \mathrm{M}$ SB203580, $25 \mu \mathrm{M}$ $\mathrm{U} 0126$ or $20 \mu \mathrm{M} \mathrm{SP} 600125)$ for $2 \mathrm{~h}$ at $37^{\circ} \mathrm{C}$, followed by incubation with WCCP-A-b $(200 \mu \mathrm{g} / \mathrm{ml})$ at $37^{\circ} \mathrm{C}$ for $24 \mathrm{~h}$. Western blot analysis was performed as described by Meng et al (36). RAW264.7 cells were rinsed twice with cold PBS and lysed in lysis buffer $(50 \mathrm{mM}$ Tris/acetate, $\mathrm{pH} 7.4,1 \mathrm{mM}$ EDTA, $0.5 \%$ Triton X-100, $150 \mathrm{mM}$ sodium chloride, $0.1 \mathrm{mM}$ PMSF and Roche incomplete protease inhibitor cocktail). Protein concentration was measured using the Bradford method. Equal amounts of protein (30 $\mu \mathrm{g}$ /lane) were separated via $12 \%$ SDS-PAGE and transferred to a PVDF membrane. The membrane was blocked in 3\% BSA at room temperature for $1 \mathrm{~h}$ and then blotted with specific antibodies, and proteins were detected using an electrochemiluminescence reagent (Tanon Science and Technology Co., Ltd.). Both the primary and secondary antibody incubations were $1 \mathrm{~h}$ at room temperature. Primary antibodies $(1: 1,000)$ against phosphorylated (p)-JNK (cat. no. 4668s), JNK (cat. no. 9252s), p-ERK (cat. no. 9101s), ERK (cat. no. 9102s), p-p38 (cat. no. 9215s) and p38 (cat. no. 9212s) were obtained from Cell Signaling Technology, Inc. The antibody against $\beta$-actin (cat. no. 612657) was purchased from BD Biosciences. HRP-conjugated goat anti-rabbit IgG (cat. no. AS014) and goat anti-mouse IgG (cat. no. AS003) secondary antibodies $(1: 5,000)$ were obtained from ABclonal Biotech Co., Ltd.

Statistical analysis. Data are presented as the mean \pm SD from $\geq 3$ independent experiments. Data were analyzed using one-way ANOVA followed by Dunnett's test for comparisons among multiple groups. Statistical analysis was performed using GraphPad Prism 8.0 software (GraphPad Prism, Inc.). $\mathrm{P}<0.05$ was considered to indicate a statistically significant difference.

\section{Results and Discussion}

Preparation of polysaccharide from $C$. cibarius. WCCP was extracted from fruiting bodies of $C$. cibarius using boiling hot 
A

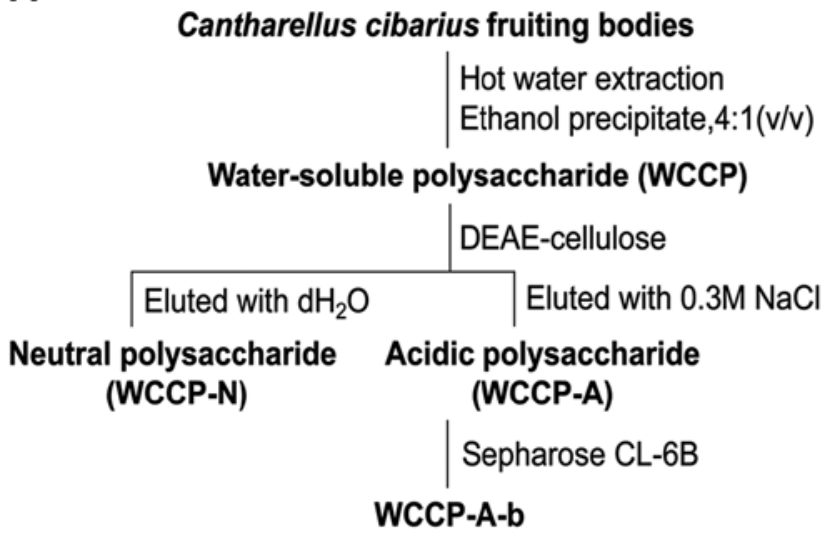

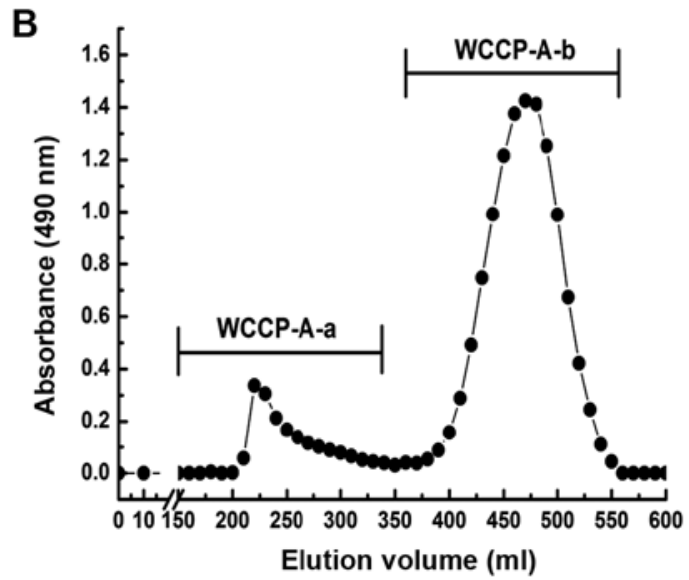

D

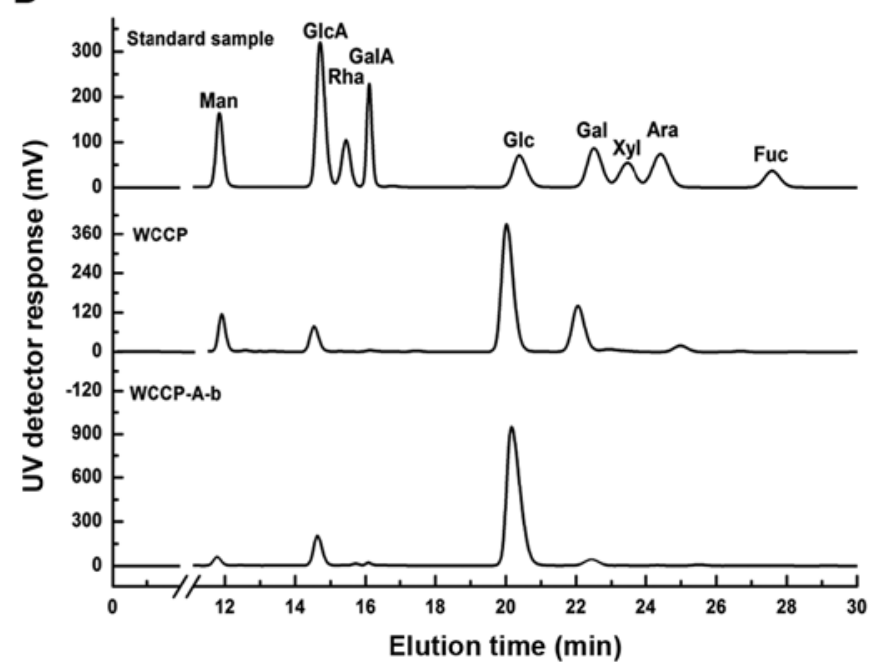

Figure 1. Extraction and purification of polysaccharide. (A) Preparation scheme of WCCP-A-b from Cantharellus cibarius. (B) Elution profile of WCCP-A on Sepharose Cl-6B column. (C) Elution profile of WCCP-A-b via high-performance gel permeation chromatography. (D) Monosaccharide composition of WCCP and WCCP-A-b. WCCP, water-soluble C. cibarius polysaccharide; A, acidic polysaccharide fraction; A-b, homogenous fraction; RI, refractive index.

water, and the yield was $5.5 \%$ relative to the dry weight of the material. WCCP contained $79.2 \%$ of total sugar, $4.2 \%$ of uronic acids and $2.8 \%$ of protein (data not shown). Moreover, it was composed of $56.0 \%$ glucose, $21.8 \%$ galactose, $10.2 \%$ mannose, $8.6 \%$ glucuronic acid and minor 3-methyl-galactose (3.4\%) (Fig. 1D). WCCP was separated into WCCP-N and WCCP-A using anion-exchange chromatography (Fig. 1A). WCCP-A was further purified using gel-permeation chromatography (Fig. 1B), and a homogeneous fraction WCCP-A-b was obtained with the yield of $64.2 \%$ relative to WCCP-A. The molecular weight of WCCP-A-b was $\sim 7.3 \mathrm{kDa}$, as determined via HPGPC (Fig. 1C). This contained glucose as the major sugar $(89.7 \%)$, followed by minor of glucuronic acid $(8.8 \%)$ (Fig. 1D).

FT-IR spectrum analysis. The FT-IR spectrum of WCCP-A-b is presented in Fig. 2. The strong absorption band at $3,381 \mathrm{~cm}^{-1}$ was attributed to the stretching vibration of $\mathrm{O}-\mathrm{H}$. The weak band near $2,894 \mathrm{~cm}^{-1}$ indicated $\mathrm{C}-\mathrm{H}$ stretching vibration. The stretching bands at $\sim 1,607 \mathrm{~cm}^{-1}$ were observed as the bending vibration of $\mathrm{O}-\mathrm{H}$. The band near $1,048 \mathrm{~cm}^{-1}$ suggested the presence of pyranose ring and the weak bands at $\sim 900 \mathrm{~cm}^{-1}$ was associated with the presence of $\beta$-linked glycosyl residues (34).

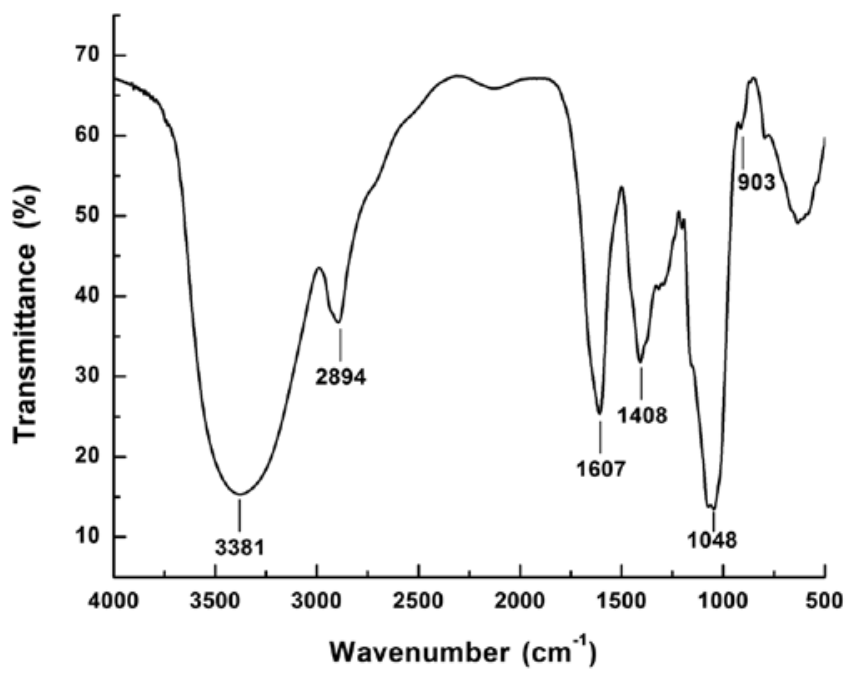

Figure 2. Fourier transform infrared spectrum of the water-soluble $C$. cibarius polysaccharide homogenous fraction (WCCP-A-b).

Methylation analysis. To determine the glycosidic linkages in WCCP-A-b, methylation analysis was performed. As 
Table I. Glycosidic linkages of water-soluble C. cibarius polysaccharide homogenous fraction (WCCP-A-b) analyzed by GC-MS .

\begin{tabular}{|c|c|c|c|}
\hline Methylated sugars & Linkages & Molar \% & Mass fragments. $\mathrm{m} / \mathrm{z}$ \\
\hline 2,3,4-Me3-Glcp & $1,6-$ & 57.4 & $101,117,129,161,173,189,233$ \\
\hline 2,4-Me2-Glcp & $1,3,6-$ & 15.2 & $117,129,159,189,233,261,305$ \\
\hline 2,4,6-Me3-Glcp & $1,3-$ & 5.0 & $101,117,129,161,189,233,277$ \\
\hline 2,3,4,6-Me4-Glcp & $1-$ & 17.3 & $101,117,129,145,161,205$ \\
\hline 2,3,6-Me3-GlcA $p^{\mathrm{a}}$ & $1,4-$ & 5.1 & $101,117,129,161,235$ \\
\hline
\end{tabular}

a2,3,6-Me3-Glcp A was deduced from 2,3,6-Me3-Glcp (GC-MS ions at m/z 101, 117, 129, 161, 235), which was produced due to the reduction of Glcp A by $\mathrm{NaBD}_{4}$ to Glc. GC-MS, gas chromatography-mass spectrometry.

Table II. Chemical shift assignments of $\mathrm{H}$ and $\mathrm{C}$ signals for water-soluble $C$. cibarius polysaccharide homogenous fraction (WCCP-A-b).

\begin{tabular}{|c|c|c|c|c|c|c|}
\hline Linkage type & 1 & 2 & 3 & 4 & 5 & 6 \\
\hline \multicolumn{7}{|l|}{$\beta-1,6-\mathrm{D}-\mathrm{Glc} p$} \\
\hline $\mathrm{H}$ & 4.44 & 3.25 & 3.41 & 3.41 & 3.55 & $4.14 ; 3.78$ \\
\hline $\mathrm{C}$ & 102.92 & 73.01 & 75.56 & 69.44 & 74.85 & 68.74 \\
\hline \multicolumn{7}{|c|}{$\beta-1,3,6-\mathrm{D}-\mathrm{Glc} p$} \\
\hline $\mathrm{H}$ & 4.44 & 3.44 & 3.67 & 3.39 & 3.55 & $4.14 ; 3.78$ \\
\hline $\mathrm{C}$ & 102.89 & 72.84 & 84.57 & 69.42 & 74.85 & 68.74 \\
\hline \multicolumn{7}{|l|}{$\beta$-1,3-D-Glc $p$} \\
\hline $\mathrm{H}$ & 4.67 & 3.25 & 3.73 & 3.32 & 3.55 & $3.85 ; 3.66$ \\
\hline $\mathrm{C}$ & 102.79 & 73.01 & 83.50 & 69.54 & 74.85 & 60.67 \\
\hline \multicolumn{7}{|l|}{$\mathrm{t}-\beta-\mathrm{D}-\mathrm{Glc} p$} \\
\hline $\mathrm{H}$ & 4.67 & 3.35 & 3.44 & 3.44 & 3.34 & $3.85 ; 3.66$ \\
\hline $\mathrm{C}$ & 102.79 & 73.04 & 75.51 & 68.15 & 75.63 & 60.67 \\
\hline \multicolumn{7}{|c|}{$\beta-1,4-\mathrm{D}-\mathrm{GlcA} p$} \\
\hline $\mathrm{H}$ & 4.97 & 3.67 & 3.79 & 3.66 & 3.87 & - \\
\hline $\mathrm{C}$ & 102.18 & 73.21 & 75.26 & 80.55 & 75.03 & 172.32 \\
\hline
\end{tabular}

$\mathrm{H}$, proton; C, carbon.

WCCP-A-b contained minor glucuronic acid, it was firstly reduced by $\mathrm{NaBD}_{4}$, then methylated, hydrolyzed and acetylated. The partially methylated alditol acetates were analyzed using GC-MS. As presented in Table I, the glycosidic linkage of glucose in WCCP-A-b was mainly in the form of 1,6-linked (57.4\%) and 1,3,6-linked (15.2\%), suggesting that its backbone was 1,6-glucan, which was branched at O-3. The DB was $\sim 20.9 \%$. Terminal glucose $(17.3 \%)$ and 1,3-linked glucose $(5.0 \%)$ were detected as side chains (Table I). It was indicated that terminal glucose may be linked to the backbone through O-3 of 1,6-linked glucose or through short 1,3-linked glucose. Moreover, 1,4-linked glucuronic acid (5.1\%) residues were detected in WCCP-A-b, which may be present in side chains (Table I).

Structure analysis by NMR spectra. The 1D/2D NMR spectra of WCCP-A-b are presented in Fig. 3 and the chemical shifts are listed in Table II. In the ${ }^{1} \mathrm{H}-\mathrm{NMR}$ spectrum (Fig. 3A), there were three anomeric proton signals at
4.97, 4.67 (the signal peaks overlapped with HOD peaks) and $4.44 \mathrm{ppm}$, which were assigned to anomeric protons of $\beta-1,4-D-G l c A p$ (37), t- $\beta$-D-Glc $p / \beta-1,3-D-G l c p$ and $\beta-1,6-\mathrm{D}-\mathrm{Glc} p / \beta-1,3,6-\mathrm{D}-\mathrm{Glc} p$ (38), respectively. The proton chemical shifts occurring in the 3.25-4.14 ppm region were $\mathrm{H} 2-\mathrm{H} 6$ of each sugar residue. In the ${ }^{13} \mathrm{C}-\mathrm{NMR}$ spectrum (Fig. 3B), six obvious signals at $\delta 102.92,73.01,75.56$, 69.44, 74.85 and $68.74 \mathrm{ppm}$ arose from C-1, C-2, C-3, C-4, C-5 and C-6 of $\beta-1,6-\mathrm{D}-\mathrm{Glc} p$ residues (39). The signals at 102.79 and $60.67 \mathrm{ppm}$ were assigned to $\mathrm{C}-1$ and $\mathrm{C}-6$ of $\mathrm{t}-\beta-\mathrm{D}-\mathrm{Glc} p$ ( $\beta-1,3-\mathrm{D}-\mathrm{Glc} p)$, respectively. The weak signal at $172.32 \mathrm{ppm}$ was assigned to carboxyl group of GlcpA.

Other proton and carbon signals of WCCP-A-b were assigned according to the HSQC spectrum (Fig. 3C). The strong cross $\mathrm{H} 1 / \mathrm{C} 1$ signal at 4.44/102.92 ppm, H3/C3 signal at 3.41/75.56 ppm and H6/C6 signal at 4.14;3.78/68.76 ppm arose from 1,6-linked $\beta$-D-Glc $p$. The strong cross $\mathrm{H} 1 / \mathrm{C} 1$ signal at 4.44/102.92 ppm, H3/C3 signal at 3.67/84.57 ppm and H6/C6 signal at $4.14 ; 3.78 / 68.76 \mathrm{ppm}$ were attributed to $1,3,6$-linked 
A

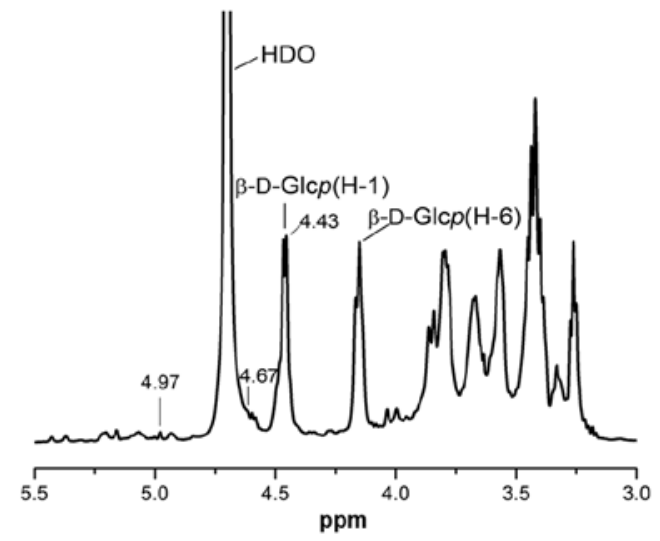

C

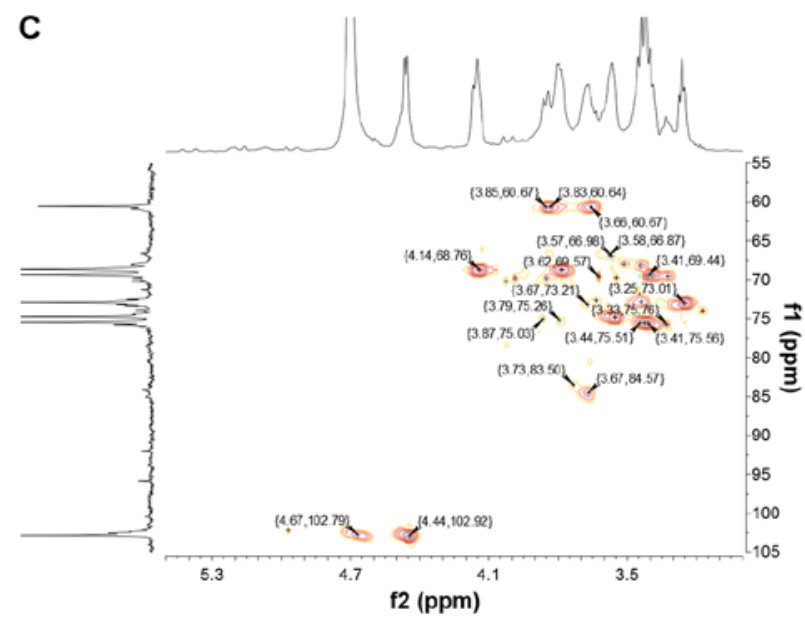

B

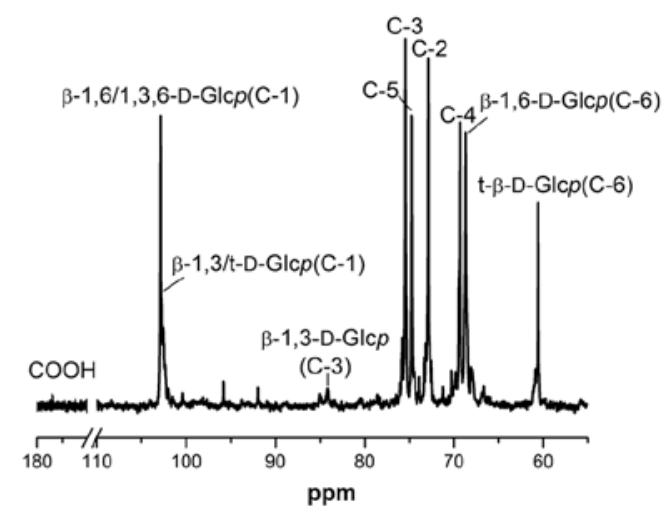

D

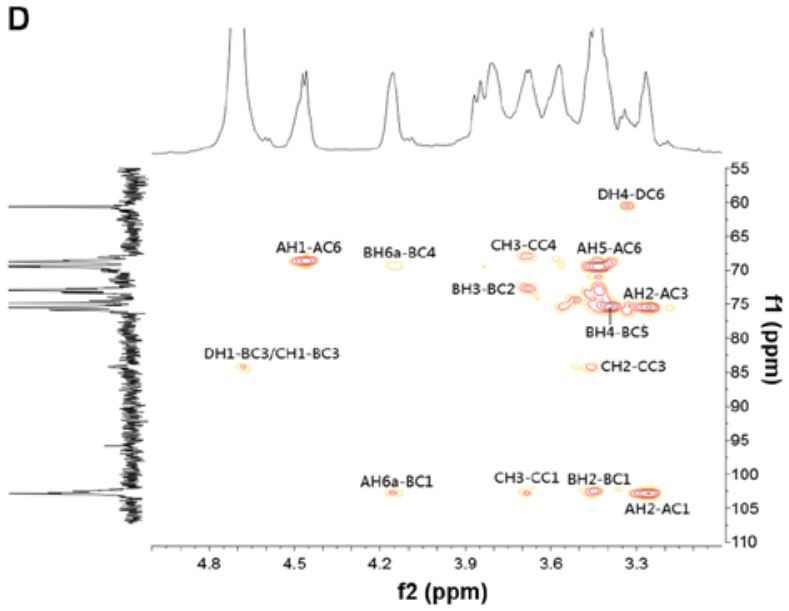

Figure 3. NMR spectra of the water-soluble C. cibarius polysaccharide homogenous fraction (WCCP-A-b). (A) ${ }^{1} \mathrm{H}$ NMR spectrum. (B) ${ }^{13} \mathrm{C}$ NMR spectrum. (C) Heteronuclear singular quantum correlation spectrum. (D) heteronuclear multiple bond correlation spectrum. NMR, nuclear magnetic resonance.

A

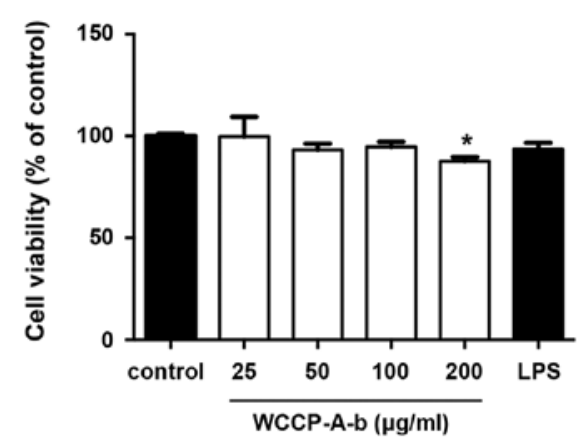

C

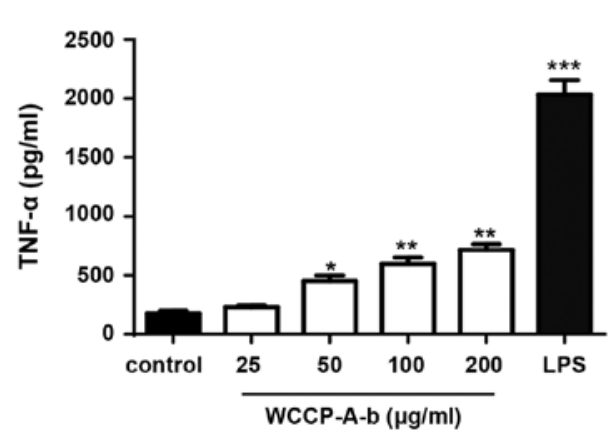

B

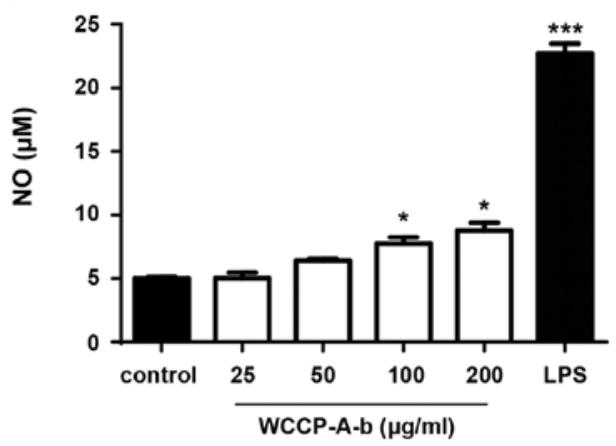

D

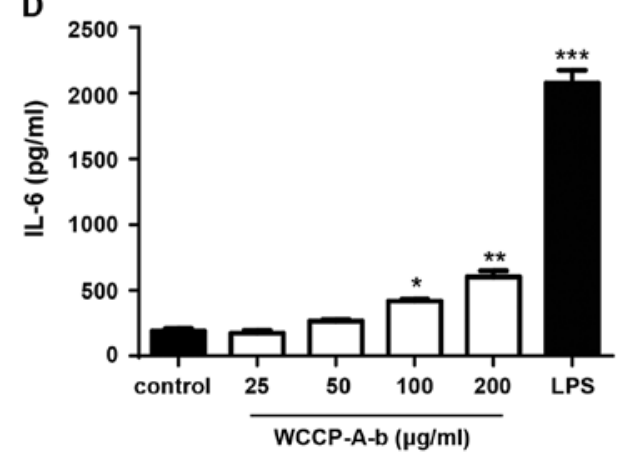

Figure 4. WCCP-A-b promotes macrophage activation. RAW264.7 cells were treated with the indicated doses of WCCP-A-b for 24 h. (A) Cell viability was determined using the MTT assay. (B) NO concentration was analyzed using Griess reagents and the secretion of the cytokines (C) TNF- $\alpha$ and (D) IL-6 was examined via ELISA. The data are presented as the mean $\pm \mathrm{SD}\left(\mathrm{n}=3\right.$ independent experiments). ${ }^{*} \mathrm{P}<0.05,{ }^{* *} \mathrm{P}<0.01$ and ${ }^{* * *} \mathrm{P}<0.001$ vs. control. WCCP-A-b, water-soluble $C$. cibarius polysaccharide homogenous fraction; LPS, lipopolysaccharide; NO, nitric oxide. 
A

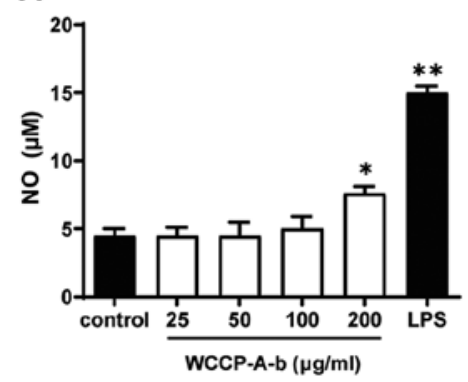

D

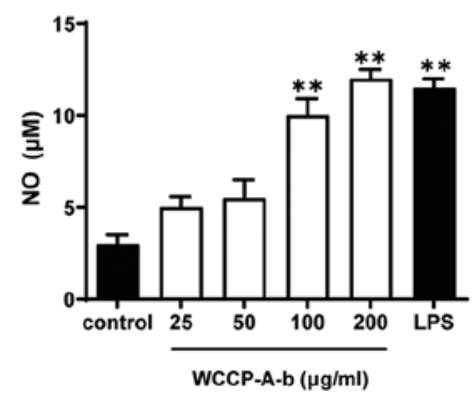

B

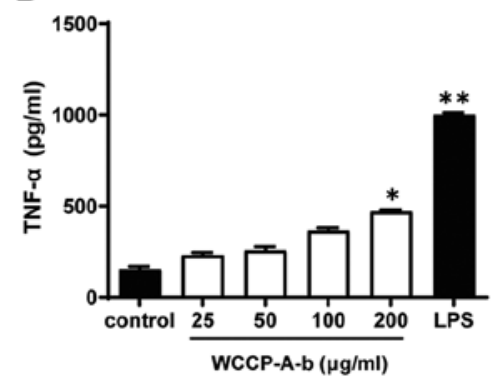

E

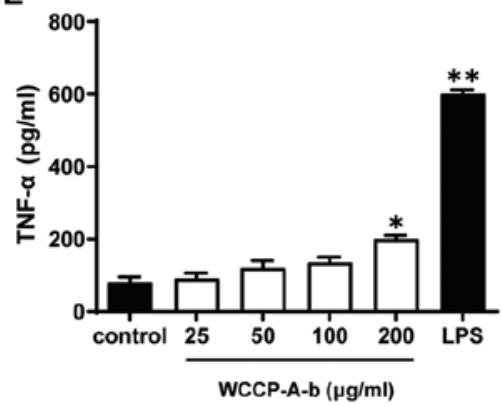

C

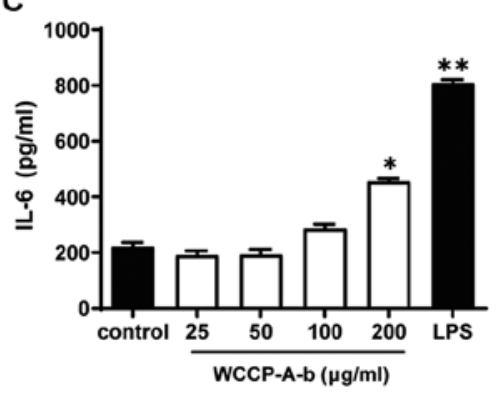

F

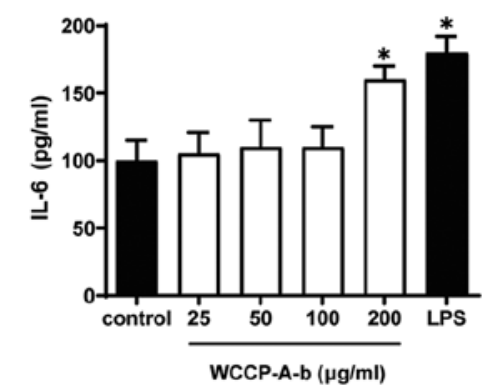

Figure 5. Immunomodulatory activities of WCCP-A-b in vitro. Effect of WCCP-A-b on (A) NO, (B) TNF- $\alpha$ and (C) IL-6 release from mouse peritoneal macrophages and on (D) NO, (E) TNF- $\alpha$ and (F) IL-6 release from bone marrow macrophages. The data are presented as the mean \pm SD ( $n=3$ independent experiments). ${ }^{*} \mathrm{P}<0.05$ and ${ }^{* *} \mathrm{P}<0.01$ vs. control. WCCP-A-b, water-soluble $C$. cibarius polysaccharide homogenous fraction; LPS, lipopolysaccharide; NO, nitric oxide.

A

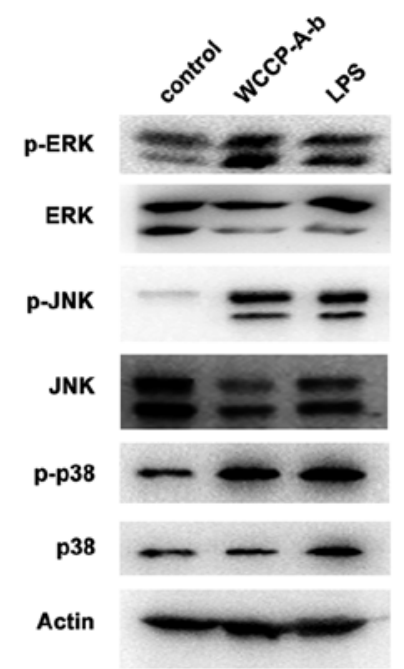

C

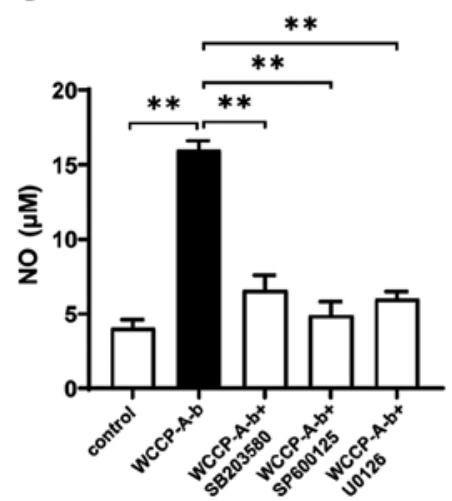

B

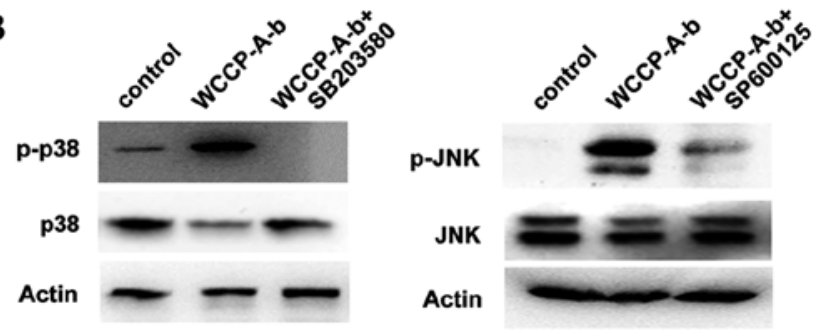

D

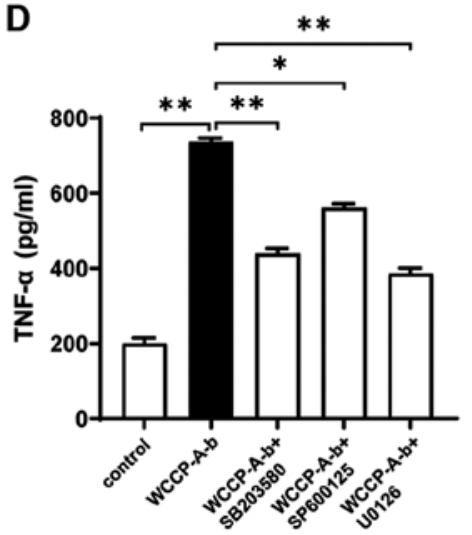

E

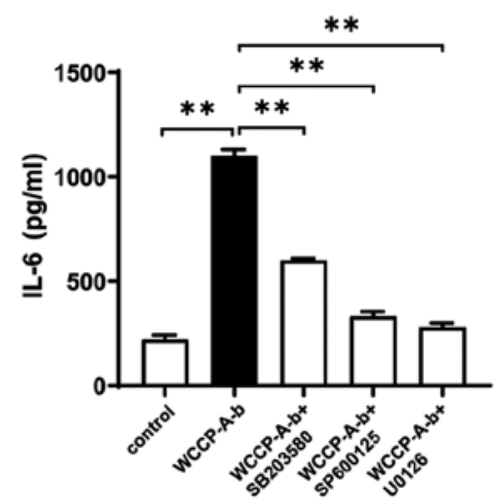

Figure 6. Effect of WCCP-A-b on MAPK signaling pathways. (A and B) Protein expression levels of p38, JNK and ERK, and their phosphorylation. (C) NO production, (D) TNF- $\alpha$ and (E) IL-6 secretion was detected using Griess reagents and ELISAs, respectively. The data are presented as the mean \pm SD (n=3 independent experiments). ${ }^{*} \mathrm{P}<0.05$ and ${ }^{* *} \mathrm{P}<0.01$. WCCP-A-b, water-soluble C. cibarius polysaccharide homogenous fraction; LPS, lipopolysaccharide; NO, nitric oxide, p-, phosphorylated. 
$\beta$-D-Glcp. The cross-peak at 4.67/102.79 and 3.85;3.66/60.67 ppm were from $\mathrm{H} 1 / \mathrm{C} 1$ and $\mathrm{H} 6 \mathrm{a} ; \mathrm{b} / \mathrm{C} 6$ of the terminal- $\beta-\mathrm{D}-\mathrm{Glc} p$, while the down-field shift at 3.73/83.50 ppm was from $\mathrm{H} 3 / \mathrm{C} 3$ of 1,3- or 1,3,6-linked $\beta$-D-Glc $p(40,41)$. Furthermore, the weak signal peak of $\mathrm{H} 1 / \mathrm{C} 1(4.97 / 102.18 \mathrm{ppm})$ and down-field shift of H4/C4 (3.66/80.55 ppm) confirmed the existence of 1,4-linked $\beta$-D-GlcA $p(42,37)$.

In the HMBC spectrum (Fig. 3D), the cross peaks of both anomeric protons and carbons of glycosyl residues AH1/AC6, $\mathrm{AH} 2 / \mathrm{AC} 1, \mathrm{AH} 6 \mathrm{a} / \mathrm{BC} 1, \mathrm{BC} 3 / \mathrm{CH} 1, \mathrm{BC} 3 / \mathrm{DH} 1, \mathrm{CC} 1 / \mathrm{CH} 3$ and $\mathrm{DC} 1 / \mathrm{DH} 2$ were observed. Due to the low amount of GlcA in WCCP-A-b, no obvious cross peaks were observed in HMBC for GlcA. Combined with the methylation analysis results, the possible structure of WCCP-A-b was proposed as a $\beta-1,6-\mathrm{D}$-glucan, which was branched at O-3 of $\beta-1,6-\mathrm{D}-\mathrm{Gl} p$ by short $\beta-1,3-\mathrm{D}-\mathrm{Glc} p$ oligosaccharides or single-unit terminal $\beta$-Glc $p$ residues. Small amounts of $\beta-1,4-\mathrm{D}-\mathrm{Glc} p \mathrm{~A}$ may also exist in side chains. According to the aforementioned analysis, WCCP-A-b may be a novel $\beta-1,6-\mathrm{D}$-glucan structure containing $\beta-1,4-\mathrm{D}-\mathrm{Glc} p \mathrm{~A}$ side chains, which to the best of our knowledge has not been previously reported.

Acidic $\beta$-glucans have been previously reported (37,43); however, their structures are different from the WCCP-A-b that was identified in the present study. A polysaccharide fraction (PSG-1-F0.2), isolated from Ganoderma atrum, also mainly consisted of glucose and glucuronic acid (37). The backbone of PSG-1-F0.2 was identified to be composed of $\beta$ - $(1 \rightarrow 3)$-glucose, which was different from WCCP-A-b. One glucan fraction (WPOPA) obtained from Pleurotus ostreatus had a similar main chain structure to WCCP-A-b, but most of the GlcpA residues were in the form of $\mathrm{t}-\beta-\mathrm{D}-\mathrm{Glc} p \mathrm{~A}$, which was notably distinguished from WCCP-A-b (43).

WCCP-A-b promotes macrophage activation. Macrophages can defend against pathogen invasion, can kill tumor cells and can improve the immune capabilities by releasing inflammatory mediators (27). NO, TNF- $\alpha$ and IL-6 serve an important role in the immune process (34). In order to investigate the immunomodulatory activity of WCCP-A-b, RAW264.7 cells were treated with WCCP-A-b. The MTT assay indicated that WCCP-A-b exhibited no cytotoxicity towards RAW264.7 cells at concentrations of $0-100 \mu \mathrm{g} / \mathrm{ml}$, but that there was a significant decrease in cell viability at $200 \mu \mathrm{g} / \mathrm{ml}$ (Fig. 4A). ELISA assays and Griess reagent were used to quantify NO, TNF- $\alpha$ and IL- 6 concentrations in the conditioned medium of RAW264.7 cells. As the positive control, LPS significantly stimulated NO, TNF- $\alpha$ and IL-6 production. Moreover, WCCP-A-b induced NO, TNF- $\alpha$ and IL- 6 production in RAW264.7 cells in a dose-dependent manner (Fig. 4B-D), with a significant difference for all at 100 and $200 \mu \mathrm{g} / \mathrm{ml}$. To further confirm these results, the aforementioned experiments were repeated using mouse peritoneal macrophages and bone marrow macrophages (Fig. 5). The results demonstrated that WCCP-A-b also induced NO, TNF- $\alpha$ and IL-6 production in mouse peritoneal macrophages (Fig. 5A-C) and bone marrow macrophages (Fig. 5D-F), with significant increases at $200 \mu \mathrm{g} / \mathrm{ml}$, indicating that WCCP-A-b may promote macrophage activation.

$\beta$-D-glucans obtained from mushrooms are effective immunomodulators and are considered as modifiers of biological responses (4). A neutral branched $\beta$-glucan extracted from the fruiting bodies of Amillariella mellea, containing $\beta$-D-(1 $\rightarrow 6)$-linked Glc $p$ as its main chain, can promote macrophage phagocytosis and increase production of NO, reactive oxygen species, TNF- $\alpha$, IL- 6 and IL- $1 \beta$ (34). Another polysaccharide, containing a higher content of $(1 \rightarrow 6)$-linked $\beta$-glucan and lower content of $\alpha$-glucan, purified from Agaricus brasiliensis increases the secretion of the pro-inflammatory cytokines IL- $1 \beta$ and TNF- $\alpha$ in phorbol myristate acetate-differentiated THP-1 cells, while it decreases pro-inflammatory effects caused by LPS, indicating promising immune activity (44). However, a branched $\beta-1,3$-glucan, derived from the fruiting bodies of Lentinus squarrosulus, is able to activate macrophages, splenocytes and thymocytes at certain concentrations (45). Therefore, the novel $\beta-1,6-\mathrm{D}$-glucan isolated from $C$. cibarius in the present study may be used as a potential natural immunostimulatory agent.

MAPK signaling pathway is involved in macrophage activation. MAPKs, including ERKs, JNKs and p38-MAPKs, have been found to be associated with macrophage activation (36). The present study investigated whether the MAPK signaling pathway was associated with WCCP-A-b-induced macrophage activation. The results indicated that WCCP-A-b increased the phosphorylation of ERK, JNK and p38 (Fig. 6A). Pre-treatment of cells with inhibitors of JNK (SP600125), ERK (U0126) and p38 (SB203580) markedly decreased the phosphorylation of ERK, JNK and p38, respectively (Fig. 6B). In addition, the secretion of NO, TNF- $\alpha$ and IL- 6 was significantly suppressed following the addition of the aforementioned inhibitors (Fig. 6C-E). Therefore, it was suggested that the MAPK signaling pathway may be involved in the macrophage activation by WCCP-A-b.

Conclusion. In the present study, an acidic $\beta$-glucan (WCCP-A-b) was purified from hot water extracted polysaccharides from the fruiting bodies of $C$. cibarius using anion exchange and gel-permeation chromatography. The backbone of WCCP-A-b was a $\beta$-D-1,6-glucan, which was branched at O-3 of Glc $p$ by $\beta-1,3-\mathrm{D}-$ Glc $p$ short chains or single-unit of $\beta$-Glc $p$ residues. Furthermore, small amounts of $\beta-1,4-\mathrm{D}-$ Glc $p$ A may be present in the side chains. WCCP-A-b possessed a macrophage activatory effect by promoting the secretion of $\mathrm{NO}$, TNF- $\alpha$ and IL-6. On a cellular mechanistic level, WCCP-A-b activated macrophages via the MAPKs signaling pathway. However, the structure-activity association of the glucan was not deeply discussed in the present study. Therefore, more studies, such as in vivo animal experiments, on the investigation of the immunomodulatory activity should be further performed. The present data indicated that the identified novel $\beta$-glucan may be used as a potent immunomodulator.

\section{Acknowledgements}

Not applicable.

\section{Funding}

The present study was supported by the Science \& Technology Major Project 'Key New Drug Creation and Manufacturing Program' (grant no. 2019ZX09735001), the Fundamental 
Research Funds for the Central Universities (grant no. 2412020FZ018), and the Jilin Province Development and Reform Commission (grant no. 2019C018).

\section{Availability of data and materials}

The datasets used and/or analyzed during the current study are available from the corresponding author on reasonable request.

\section{Authors' contributions}

LS and YZ conceived the study and revised the manuscript. YQ purified and characterized the polysaccharides and drafted the manuscript. XZ and $\mathrm{HG}$ performed the polysaccharide extraction. YM and YW performed the macrophage activation experiments and confirmed the authenticity of the data. All authors have read and approved the final manuscript.

\section{Ethics approval and consent to participate}

The present study was approved by the Institutional Animal Care and Use Committee of Northeast Normal University (approval no. AP20151009) and was conducted in accordance with the National Standards of the People's Republic of China Laboratory Animal-Guideline for Ethical Review of Animal Welfare.

\section{Patient consent for publication}

Not applicable.

\section{Competing interests}

The authors declare that they have no competing interests.

\section{References}

1. Manzi P, Aguzzi A and Pizzoferrato L: Nutritional value of mushrooms widely consumed in Italy. Food Chem 73: 321-325, 2001.

2. Sun Y, Zhang M and Fang Z: Efficient physical extraction of active constituents from edible fungi and their potential bioactivities: A review. Trends Food Sci Technol 105: 468-482, 2020.

3. Rathore H, Prasad S and Sharma S: Mushroom nutraceuticals for improved nutrition and better human health: A review. PharmaNutrition 5: 35-46, 2017.

4. Kothari D, Patel S and Kim SK: Anticancer and other therapeutic relevance of mushroom polysaccharides: A holistic appraisal Biomed Pharmacother 105: 377-394, 2018.

5. Ruthes AC, Smiderle FR and Iacomini M: D-glucans from edible mushrooms: A review on the extraction, purification and chemical characterization approaches. Carbohydr Polym 117: 753-761, 2015.

6. Bhanja SK, Rout D, Patra P, Sena IK, Nandan CK and Islam SS: Water-insoluble glucans from the edible fungus Ramaria botrytis Bioactive Carbohydrates and Dietary Fibre 3: 52-58, 2014.

7. Palacios I, García-Lafuente A, Guillamón E and Villares A: Novel isolation of water-soluble polysaccharides from the fruiting bodies of Pleurotus ostreatus mushrooms. Carbohydr Res 358: 72-77, 2012

8. Chakraborty I, Mondal S, Rout D and Islam SS: A Water-insoluble (1->3)-beta-D-glucan from the alkaline extract of an edible mushroom Termitomyces eurhizus. Carbohydr Res 341: 2990-2993, 2006.

9. Smiderle FR, Alquini G, Tadra-Sfeir MZ, Iacomini M, Wichers HJ and Van Griensven LJ: Agaricus bisporus and Agaricus brasiliensis $(1 \rightarrow 6)-\beta$-D-glucans show immunostimulatory activity on human THP-1 derived macrophages. Carbohydr Polym 94: 91-99, 2013.
10. Castro-Alves VC and Nascimento JROD: $\alpha$ - and $\beta$-d-Glucans from the edible mushroom Pleurotus albidus differentially regulate lipid-induced inflammation and foam cell formation in human macrophage-like THP-1 cells. Int J Biol Macromol 111: 1222-1228, 2018.

11. Smiderle FR, Baggio $\mathrm{CH}$, Borato DG, Santana-Filho AP, Sassaki GL, Iacomini M and Van Griensven LJ: Anti-inflammatory properties of the medicinal mushroom Cordyceps militaris might be related to its linear $(1 \rightarrow 3)-\beta$-D-glucan. PLoS One 9: e110266, 2014.

12. Hida TH, Kawaminami H, Ishibashi K, Miura NN, Adachi Y and Ohno N: Oral administration of soluble $\beta$-glucan preparation from the cauliflower mushroom, Sparassis crispa (Higher Basidiomycetes) modulated cytokine production in mice. Int J Med Mushrooms 15: 525-538, 2013.

13. Misaki A, Kakuta M, Sasaki T, Tanaka M and Miyaji H: Studies on interrelation of structure and antitumor effects of polysaccharides: Antitumor action of periodate-modified, branched (1 goes to 3)-beta-d-glucan of auricularia auricula-judae, and other polysaccharides containing (1 goes to 3 )-glycosidic linkages. Carbohydr Res 92: 115-129, 1981.

14. Misaki A, Kawaguchi K, Miyaji H, Nagae H, Hokkoku S, Kakuta M and Sasaki T: Structure of pestalotan, a highly branched (1-3)-beta-d-glucan elaborated by Pestalotia, sp. 815 , and the enhancement of its antitumor activity by polyol modification of the side chains. Carbohydr Res 129: 209-227, 1984.

15. Zhang Y, Konga H, Fang Y, Nishinari K and Phillips GO: Schizophyllan: A review on its structure, properties, bioactivities and recent developments. Bioactive Carbohydrate and Dietary Fiber 1: 53-71, 2013.

16. Lehtovaara BC and Gu FX: Pharmacological, structural, and drug delivery properties and applications of $1,3-\beta$-glucans. J Agric Food Chem 59: 6813-6828, 2011.

17. Synytsya A, Míčková K, Synytsya A, Jablonský I, Spěváček J, Erban V, Kovárík ková E and Copíková J: Glucans from fruit bodies of cultivated mushrooms Pleurotus ostreatus and Pleurotus eryngii: Structure and potential prebiotic activity. Carbohydr Polym 76: 548-556, 2009.

18. Oishi Y and Manabe I: Macrophages in inflammation, repair and regeneration. Int Immunol 30: 511-528, 2018.

19. Martinez FO and Gordon S: The M1 and M2 paradigm of macrophage activation: Time for reassessment. F1000Prime Rep 6: 13, 2014.

20. Grivennikov SI, Greten FR and Karin M: Immunity, inflammation, and cancer. Cell 140: 883-899, 2010.

21. Liu KS, Zhang C, Dong HL, Li KK, Han QB, Wan Y, Chen R, Yang F, Li HL, Ko CH and Han XQ: GSP-2, a polysaccharide extracted from Ganoderma sinense, is a novel toll-like receptor 4 agonist. PLoS One 14: e0221636, 2019.

22. Wu D, Tang C, Liu Y, Li Q, Wang W, Zhou S, Zhang Z, Cui F and Yang Y: Structural elucidation and immunomodulatory activity of a $\beta$-D-glucan prepared by freeze-thawing from Hericium erinaceus. Carbohydr Polym 222: 114996, 2019.

23. Han XQ, Li WJ, Ko CH, Gao XM, Han CX and Tu PF: Structure characterization and immunocompetence of a glucan from the fruiting bodies of Cantharellus cibarius. J Asian Nat Prod Res 15: 1204-1209, 2013.

24. Nowacka-Jechalke N, Nowak R, Juda M, Malm A, Lemieszek M, Rzeski W and Kaczyński Z: New biological activity of the polysaccharide fraction from Cantharellus cibarius and its structural characterization. Food Chem 268: 355-361, 2018.

25. Lemieszek MK, Nunes FM, Marques G and Rzeski W: Cantharellus cibarius branched mannans inhibits colon cancer cells growth by interfering with signals transduction in NF- $\mathrm{KB}$ pathway. Int J Biol Macromol 134: 770-780, 2019.

26. Nyman AA, Aachmann FL, Rise F, Balance S and Samuelsen AB: Structural characterization of a branched $(1 \rightarrow 6)$ - $\alpha$-mannan and $\beta$-glucans isolated from the fruiting bodies of Cantharellus cibarius. Carbohydr Polym 146: 197-207, 2016.

27. Yang G, Qu Y, Meng Y, Wang Y, Song C, Cheng H, Li X, Sun L and Zhou Y: A novel linear 3-O-methylated galactan isolated from Cantharellus cibarius activates macrophages. Carbohydr Polym 214: 34-43, 2019.

28. Meng Y, Qu Y, Wu W, Chen L, Sun L, Tai G, Zhou Y and Cheng H: Galactan isolated from Cantharellus cibarius modulates antitumor immune response by converting tumor-associated macrophages toward M1-like phenotype. Carbohydr Polym 226: 115295, 2019.

29. Ana V, Ana GL, Eva G and Laura MV: Separation and characterization of the structural features of macromolecular carbohydrates from wild edible mushrooms. Bioactive Carbohydrates and Dietary Fibre 2: 15-21,2013. 
30. Dubois M, Gilles K, Hamilton JK, Rebers PA and Smith F: A colorimetric method for the determination of sugars. Nature 168: $167,1951$.

31. Blumenkrantz N and Asboe-Hansen G: New method for quantitative determination of uronic acids. Anal Biochem 54: 484-489, 1973.

32. Sedmak JJ and Grossberg SE: A rapid, sensitive, and versatile assay for protein using Coomassie brilliant blue G250. Anal Biochem 79: 544-552, 1977.

33. Zhang X, Yu L, Bi H, Li X, Ni W, Han H, Li N, Wang B, Zhou Y and Tai G: Total fractionation and characterization of the water-soluble polysaccharides isolated from Panax ginseng C. A. Meyer. Carbohydr Polym 77: 544-552, 2009.

34. Yan J, Han Z, Qu Y, Yao C, Shen D, Tai G, Cheng H and Zhou Y: Structure elucidation and immunomodulatory activity of a $\beta$-glucan derived from the fruiting bodies of Amillariella mellea. Food Chem 240: 534-543, 2018.

35. Needs PW and Selvendran RR: Avoiding oxidative degradation during sodium hydroxide/methyl iodide-mediated carbohydrate methylation in dimethyl sulfoxide. Carbohydr Res 245: 1-10, 1993.

36. Meng Y, Yan J, Yang G, Han Z, Tai G, Cheng H and Zhou Y: Structural characterization and macrophage activation of a hetero-galactan isolated from Flammulina velutipes. Carbohydr Polym 183: 207-218, 2018.

37. Zhang $\mathrm{H}$, Nie S, Cui SW, Xu M, Ding $H$ and Xie $M$ : Characterization of a bioactive polysaccharide from Ganoderma atrum: Re-elucidation of the fine structure. Carbohydr Polym 158: 58-67, 2017.

38. Han XQ, Yue GL, Yue RQ, Dong CX, Chan CL, Ko CH, Cheung WS, Luo KW, Dai H, Wong CK, et al: Structure elucidation and immunomodulatory activity of a beta glucan from the fruiting bodies of Ganoderma sinense. PLoS One 9: e100380, 2014.

39. Siu KC, Xu L, Chen X and Wu JY: Molecular properties and antioxidant activities of polysaccharides isolated from alkaline extract of wild Armillaria ostoyae mushrooms. Carbohydr Polym 137: 739-746, 2016.
40. Oliveira KS, Di Bastiani M, Cordeiro LM, Costa MF, Toledo KA, Iacomini M, Babosa AM, Dekker RF and Nascimento VM: $(1 \rightarrow 6)$ - and $(1 \rightarrow 3)(1 \rightarrow 6)$ - $\beta$-glucans from Lasiodiplodia theobromae MMBJ: Structural characterization and pro-inflammatory activity. Carbohydrate Polymers 133: 539-546, 2015.

41. Ruthes AC, Carbonero ER, Córdova MM, Baggio CH,Sassaki GL, Gorin PA, Santos AR and Iacomini M: Fucomannogalactan and glucan from mushroom Amanita muscaria: Structure and inflammatory pain inhibition. Carbohydr Polym 98: 761-769, 2013.

42. Du XJ, Zhang JS, Yang Y, Ye LB, Tang QJ, Jia W, Liu Y, Zhou S, Hao R Gong CY and Pan Y: Structural elucidation and immuno-stimulating activity of an acidic heteropolysaccharide (TAPA1) from Tremella aurantialba. Carbohydr Res 344: 672-678, 2009.

43. Yan J, Zhu L, Qu Y, Qu X, Mu M, Zhang M, Muneer G, Zhou Y and Sun L: Analyses of active antioxidant polysaccharides from four edible mushrooms. Int J Biol Macromol 123: 945-956, 2019.

44. Smiderle FR, Ruthes AC, van Arkel J, Chanput W, Iacomini M, Wichers HJ and VanGriensven LJ: Polysaccharides from Agaricus bisporus and Agaricus brasiliensis show similarities in their structures and their immunomodulatory effects on human monocytic THP-1 cells. BMC Complement Altern Med 11: 58 , 2011.

45. Bhunia SK, Dey B, Maity KK, Patra S, Mandal S, Maiti S, Maiti TK, Sikdar SR and Islam SS: Isolation and characterization of an immunoenhancing glucan from alkaline extract of an edible mushroom, Lentinus squarrosulus (Mont.) Singer. Carbohydr Res 346: 2039-2044, 2011.

(i) $\odot$ This work is licensed under a Creative Commons Attribution-NonCommercial-NoDerivatives 4.0 International (CC BY-NC-ND 4.0) License. 